\title{
Amylose-lipid complex as a measure of variations in physical, mechanical and barrier attributes of rice starch- I - carrageenan biodegradable edible film
}

Rahul Thakur, Penta Pristijono, John B. Golding, Costas E. Stathopoulos, Christopher J. Scarlett, Michael Bowyer, Sukhvinder P. Singh and Quan V. Vuong

This is the accepted manuscript () 2017, Elsevier Licensed under the Creative Commons AttributionNonCommercial-NoDerivatives 4.0 International: http://creativecommons.org/licenses/by-nc-nd/4.0/

\section{(c)) EY-NC-ND}

The published article is available from doi:

10.1016/j.fpsl.2017.10.002 
1 Amylose-lipid Complex as a Measure of Variations in Physical, Mechanical and Barrier

2 Attributes of Rice Starch- 1 -Carrageenan Biodegradable Edible Film

3 Rahul Thakur ${ }^{a^{*}}$, Penta Pristijono ${ }^{\text {a }}$, John B. Golding ${ }^{\text {a, c }}$, Costas E. Stathopoulos ${ }^{b}$, Christopher

4 J. Scarlett ${ }^{\text {a }}$, Michael Bowyer ${ }^{\text {a }}$, Sukhvinder P. Singh ${ }^{\text {a, c, }}$ Quan V. Vuong ${ }^{\text {a* }}$

$5 \quad$ a School of Environmental and Life Sciences, University of Newcastle, Ourimbah, NSW 2258,

6 Australia

$7 \quad{ }^{b}$ Division of Food and Drink, School of Science, Engineering and Technology, University of 8 Abertay, Dundee DD1 1HG, UK

$9 \quad{ }^{c}$ NSW Department of Primary Industries, Ourimbah, NSW 2258, Australia

*Correspondence to:

13 R. Thakur

14 E mail: $\underline{\text { Rahul.thakur@uon.edu.au }}$

15 School of Environmental and Life Sciences, Faculty of Science and Information Technology,

16 University of Newcastle, Brush Road, Ourimbah, NSW 2258, Australia.

17 Q. V. Vuong

18 School of Environmental and Life Sciences, Faculty of Science and Information Technology,

19 University of Newcastle, Brush Road, Ourimbah, NSW 2258, Australia. 


\section{Abstract}

Improvements in the hygroscopic properties of starch based films are important to strengthen

24 their mechanical properties. The effects of different hydrophobic components-butyric acid (BA, C4:0), lauric acid (LA, C12:0), palmitic acid (PA, C16:0), oleic acid (OA, C18:1), stearic acid (SA, C18:0) and sucrose fatty acid ester (FAEs) on the rice starch (RS)-1-carrageenan (1car) composite films were investigated. Scanning electron microscopy (SEM), differential scanning calorimetry (DSC), thermogravimetric analysis (TGA) in combination with amyloselipid complexing index $(\mathrm{CI})$ were used to characterise the changes in structure and properties of edible films. The SEM results showed that the surface of films became smoother after the incorporation of fatty acids. Carbon-chain length was a major determinant of CI formation which further influenced the attributes of RS-1-car films. The addition of FAEs to RS-1-car improved film thickness, permeability, transparency, tensile properties (TS) and could be used to tailor biodegradable edible films with enhanced properties and future fruit coating applications.

Keywords: Carrageenan; Fatty acids; Hydrophobic; Packaging, Starch. 


\section{Introduction}

45

Edible packaging based on polysaccharides has been studied as a potential substitute for nonbiodegradable synthetic materials (Cerqueira, Souza et al. 2012). Among the different polysaccharides, starch is one of the most promising candidate for the manufacturing of biodegradable edible films (Liu, Sun et al. 2016). Different starch sources have been investigated as an economical edible film material with good packaging properties (Thakur, Saberi et al. 2016).

Rice is one of the most important foods and is produced widely around the world. However, during harvest and packing, many rice grains crack or break resulting in a reduction of eating quality and lower prices (Bhat and Riar 2016). This lower grade underutilized material can be used as a starch source for the manufacturing of edible films and coatings. Starch functional properties are dependent on water (Wang and Copeland 2012) and like other starch sources, rice starch also has a great affinity to interact with water and this interaction has a negative impact on the films barrier and mechanical properties (González and Villanueva 2011). Moreover, lack of fragility and brittleness exhibited during starch thermoformation, limits their potential for packaging applications. Therefore, starch alone cannot form a film with satisfactory mechanical and permeability properties unless it is chemically modified, blended with other biopolymer or plasticized (Dhall 2013).

Applications of plasticizers for improving the limitations of starch films and coatings have led to the development of safe and novel solutions (Karbowiak, Hervet et al. 2006, Kowalczyk and Baraniak 2011, Vieira, da Silva et al. 2011). Fatty acids, epoxidized triglyceride vegetable oils from soybean oil, linseed oil, castor oil, sunflower oil and fatty acid esters (FAEs) are commonly studied hydrophobic components used to improve film hygroscopic properties (Vieira, da Silva et al. 2011). 
The incorporation of lipids into the film matrix is a strategy to improve the water barrier properties of edible film. However, their sole utilization may compromise with the film mechanical properties (Rocca-Smith, Marcuzzo et al. 2016) due to phase separation (incompatibility of materials) (Acosta, Jiménez et al. 2015). Moreover, water barrier properties of emulsion based edible films depends on the nature of lipids, chain length of the fatty acids and structure of dried film (Slavutsky and Bertuzzi 2016). Furthermore, starch functional properties and its interactions with different components, particularly with water and lipids, are of great interest to the food and packaging industries (Copeland, Blazek et al. 2009). These interactions are the basis of the selection of compatible component (s) into the film matrix. In the multi-scale structure of granules and the changes they undergo during the processing is the major determinant of starch functionality (Wang, Zhang et al. 2016). The starch granule, helical structure of amylose is occupied by the H-bonds which provide hydrophilicity to the molecule, and assist in forming complexes with the free fatty acids, fatty acids components of glycerides and iodine molecules. These complexes between amylose and lipids are generally described in terms of complexing index $(\mathrm{CI})$ formation as evaluated by reduction in their iodine binding capacity (Kawai, Takato et al. 2012). According to Wang, Wang et al. (2016), these interactions varies with the fatty acid component and significantly modify the properties and functionalities of starches. Hence, it becomes more important to find out a suitable emulsion with compatible fatty acid component to the starch material to produce good film properties. To the best of our knowledge there is no such study available in the literature reporting the effect of amyloselipid complex formation ability of different hydrophobic components on the attributes of rice starch-1-car edible film. Therefore, this novel study investigated the use of different fatty acids as a hydrophobic component in the rice starch/carrageenan based coating material where the objective was to investigate the influence of hydrophobic components, saturated (palmitic, stearic, lauric acid), unsaturated (oleic and butyric acid) and fatty acid ester on the 
microstructural, physical (thickness, solubility), mechanical (tensile strength and elongation at break), barrier (water vapour permeability) and optical properties of starch-carrageenan films.

\section{Materials and methods}

\subsection{Materials}

Rice grains (Oryza sativa var. Reiziq) were obtained from Sunrice (Sun Rice, Leeton Australia). Stearic acid, palmitic acid, lauric acid, butyric acid, oleic acid and Tween ${ }^{2} 20$ were purchased from Sigma Aldrich, USA. The 1-car (Chondrus crispus) was purchased from Melbourne Food ingredient depot, Australia. Sucrose fatty acid ester was from Tokyo chemical industry co. Ltd Japan. Glycerol was from Ajax Finechem Pty. Ltd, Australia. Starch isolation and characterisation of its chemical composition is described elsewhere (Thakur, Saberi et al. 2016).

\subsection{Methods}

\subsubsection{Film solution}

Dispersion solution was prepared according to the method described by Thakur, Saberi et al. (2016). Film solution was prepared in two steps.

Step-1: Starch solution (2\%) was prepared by heating the starch-water mixture at $85^{\circ} \mathrm{C}$ using hot plate magnetic stirrer (180 rpm) with constant agitation for $15 \mathrm{~min}$.

Step-2: The 1-carrageenan $(2 \%)$ was heated in water at $80{ }^{\circ} \mathrm{C}$ with constant stirring $(200 \mathrm{rpm})$ till the clear transparent solution was formed.

After mixing the solution in step-1 and step-2 liquid fatty acids $(0.6 \%)$ were added with subsequent addition of Tween®20 (0.2\%) and glycerol (1\%). The final mixture was stirred for 

20 minutes and cooled down to the room temperature before casting. $20 \mathrm{ml}$ of final film solution was poured into petri plates and dried in the oven for $24 \mathrm{~h}$ under controlled conditions $\left(35^{\circ} \mathrm{C}, \mathrm{RH} 50 \%\right)$. For evaluation films were peeled off and conditioned at $27^{\circ} \mathrm{C}, \mathrm{RH} 60 \%$ for $72 \mathrm{~h}$

\subsubsection{Complexing index (CI) of starch-fatty acid mixture}

The CI of starch-fatty acid mixture was calculated by the reduction in the iodine binding capacity as explained by Wang, Wang et al. (2016) with minor modifications. Starches depending on grain types and varieties contain varying amount of monoacyl lipids inside the granules (Wani, Singh et al. 2012). The starch used in this experiment was defatted before use and the fat content was reported in our previous work (Thakur, Pristijono et al.). Starch-fatty acid physical mixture was prepared by dissolving $5 \mathrm{mmol}$ of fatty acid in $50 \mathrm{ml}$ ethanol under magnetic stirring. $5 \mathrm{~g}$ starch was added to the mixture and stirred continuously till the complete evaporation of ethanol. $400 \mathrm{mg}$ of prepared starch-fatty acid mixture was mixed with $5 \mathrm{ml}$ distilled water in a $50 \mathrm{ml}$ centrifuge tube. The mixture was thermally processed at $92.5^{\circ} \mathrm{C}$ for 10 minutes to completely gelatinize the starch material. After cooling at room temperature, 25 $\mathrm{ml}$ of water was added and tubes were vortexed for 3 minutes before $2 \mathrm{ml}$ of iodine solution $\left(2.0 \% \mathrm{KI}+1.3 \% \mathrm{I}_{2}\right)$ was added. The mixture was mixed completely by end to end rotation. Absorbance of the final solution was measured at $548 \mathrm{~nm}$ and CI was calculated using the equation (1). All samples were tested in triplicates and results were averaged.

$$
C I=\left(\frac{A_{((\text {without fatty acid })}-A_{(\text {with fatty acid })}}{A_{(\text {without } \text { fatty } \text { acid })}}\right) * 100
$$

\section{2.3 Edible film properties}

\subsubsection{Physical properties}


137 A digital micrometer (Mitutoyo, Co., Code No. 543-551-1, Model ID-F125, 139 Japan;

138

139

\subsubsection{Permeability property}

\subsubsection{Water vapour permeability (WVP)}

WVP was measured gravimetrically using ASTM E96-92 method described by Martins, Cerqueira et al. (2012). Briefly, film samples were sealed on a permeation cell (aluminium cup containing $10 \mathrm{gm} \mathrm{CaCl}_{2}$ granules; $0 \% \mathrm{RH}$ ) and placed in a desiccator containing $\mathrm{NaCl}$ solution $\left(75 \% \mathrm{RH}\right.$ at $\left.25^{\circ} \mathrm{C}\right)$. Water vapour transport was determined using the weight gain of the cell at a steady state of transfer. Changes in the weight of the cell were recorded and plotted as a function of time. The slope of each line was evaluated by linear regression $\left(\mathrm{R}^{2}>0.99\right)$, and the water vapour transmission was calculated through the slope of the straight line $(\mathrm{g} / \mathrm{s})$ divided by the test area $\left(\mathrm{m}^{2}\right)$. After the permeation tests, the film thickness was measured and WVP $(\mathrm{g}$ $\mathrm{Pa}^{-1} \mathrm{~s}^{-1} \mathrm{~m}^{-1}$ ) was calculated as:

$\mathrm{WVP}=\frac{\Delta m}{A \Delta t} \frac{X}{\Delta P}$

$\Delta m / \Delta t=$ weight of moisture gain per unit time $\left(\mathrm{gs}^{-1}\right)$ and can be calculated by the slope of the graph. $A=$ area of the exposed film surface $\left(\mathrm{m}^{2}\right), T=$ thickness of the film (mm), $\Delta P=$ represents the water vapour pressure difference inside and outside of the film $(\mathrm{Pa})$.

\subsubsection{Mechanical properties}

\subsubsection{Tensile strength (TS) and elongation at break (EAB)}


159 Tensile strength (TS) and elongation at break (EAB) was determined with Texture Analyzer 160 (LLOYD Instrument LTD, Fareham, UK) using ASTM standard method D 882-91 (Martins, 161 Cerqueira et al. 2012). Preconditioned (60\% RH) films (15 x $40 \mathrm{~mm})$ were placed between the 162 tensile grips with $40 \mathrm{~mm}$ separation and $1 \mathrm{~mm} / \mathrm{s}$ crosshead speed respectively. 10 film samples 163 of each type of films were replicated. TS was expressed in $\mathrm{Nm}^{2}$ and $\mathrm{EAB}$ was expressed in 164 percentage.

\subsubsection{Optical and light barrier properties}

\subsubsection{Film Opacity and colour}

Light barrier properties of film were measured by using (Cary 50 Bio UV-Visible spectrophotometer) by exposing the film samples to light absorption at wavelength $550 \mathrm{~nm}$. Rectangular piece of the film samples were measured by placing into a spectrophotometer test cell directly. Transparency of film was calculated according to the following formula:

$$
T=\frac{A(550)}{X}
$$

172 Where, $\mathrm{A}_{550}$ is the absorbance at $550 \mathrm{~nm}$ and $\mathrm{X}$ is the film thickness in $\mathrm{mm}$. Opacity is the 173 measure of transparency, higher opacity corresponds to the lower transparency of film samples. 174 Colour property of film was measured using a portable chroma meter (Minolta CR-300 Japan). 175 CIELab colour profile was used to expressed the $L$ (whiteness) to - $a$ (greenness) to $+a$ (redness) and $-b$ (blueness) to $+b$ (yellowness).

$$
\Delta \mathrm{E}=\left[\left(L_{\text {film }}-L_{\text {standard }}\right)^{2}+\left(a_{\text {film }}-a_{\text {standard }}\right)^{2}+\left(b_{\text {film }}-b_{\text {standard }}\right)^{2}\right]^{1 / 2}
$$

\subsection{Film characterisation}




\subsubsection{Microstructural analysis- scanning electron microscopy (SEM)}

181

182

183

184

Film morphology was studied by using scanning electron microscope (JEOL, JSM 6300 SEM, JEOL, and Tokyo, Japan). Film samples were stored in desiccator for 1 week to ensure the absence of water in the sample (theoretical $\mathrm{RH}$ in desiccator $0 \%$ ).Film pieces were mounted on the copper stubs, gold coated and observed using an accelerating voltage of $10 \mathrm{kV}$ under high vacuum mode.

\subsubsection{Differential scanning calorimetry (DSC)}

Thermal properties of rice starch films were determined by using differential scanning calorimeter (DSC) model 60-A, Shimadzu Corporation, Kyoto Japan, equipped with thermal analyzer (TA-60WS). The film sample were completely dried in the desiccator for one week and moisture content was $<3 \%$ was observed (data not shown). For DSC analysis, film samples were contained in hermetically sealed aluminum pans and heated from 25 to $200^{\circ} \mathrm{C}$ at a rate of $10^{\circ} \mathrm{C} / \mathrm{min}$. Changes in the phases or state and corresponding enthalpies $(\Delta \mathrm{H})$ were determined.

\subsubsection{Thermogravimetric analysis}

Thermal stability of the film samples were analyzed by thermogravimetric analyzer (TGA), model TGA-50, Shimadzu Corporation, Kyoto Japan. Samples were placed in the balance system and heated from $20^{\circ} \mathrm{C}$ to $500^{\circ} \mathrm{C}$ at a heating rate of $10{ }^{\circ} \mathrm{C}$ min- 1 (Martins, Cerqueira et al. 2012).

\subsubsection{Statistical analysis}

Statistical analysis was performed by using SPSS 23.0.0 statistical software for windows (IBM SPSS statistics version 24.0 Inst., Cary, North Carolina, USA). All measurements were performed in triplicate and the results reported means. One way ANOVA was used to analyse 

the data. The mean values were evaluated using Duncan test with $p<0.05$ as statistical significance.

\section{Results and discussion}

\subsection{Film microstructure}

The structural morphology of the film surfaces with different fatty acids incorporated in the RS-1-car hydrocolloidal mixture is presented in Fig 1. Discontinuous matrix with rough irregular ridged structure was observed in case of control films (without fatty acid) Fig1.f. Fatty acids treated films showed relatively smoother and uniform surface compared with pure films, manifesting a regular and homogeneous matrix with good structural integrity. More finely distribution of polymer-fatty acid mixture was observed in the surface morphology of films treated with FAEs, LA, PA and OA signifying the compatibility of ingredients in the film matrix (Fig 1. g, c, a, d). However, non-uniformity in the surface texture of films treated with SA was observed (Fig 1.b) which may be due to the presence of unevenly dispersed lipid component on the RS-ı-car matrix. Similar results have been observed by Jiménez, Fabra et al. (2012) where SA was found to be clearly separated in a dispersed matrix. Moreover, presence of small discontinuous zones distributed along the network was observed where butyric acid was used in the RS-1-car mixture (Fig 1.e). The most possible explanation behind this trend may be the formation of preferential channel occurred during the drying of film. Chiumarelli and Hubinger (2014) showed that the miscibility of fatty acids with starch based films caused lipid aggregation as a result of solvent evaporation during drying. The results of SEM study showed that degree of homogeneity and heterogeneity of film matrix depended on the compatibility of the hydrophobic component and nature of lipid added into the mixture. 
227 CI describes the capacity of amylose to bind with the fatty acids and indicates the reduced availability of amylose to form an inclusion complex with iodine (Liu, Sun et al. 2016). CI complex of starch with different hydrophobic components was determined to confirm the thermal stability of starch-fatty acid complexes as influenced the functional attributes of RS-1car edible films. The result showed that CI values were ranged from $15.6 \%$ to $41.8 \%$ (Table 1 ) and significant differences were exists between the fatty acids. Variation in CI has been shown to exists due to the tendency of fatty acids to bind with amylose helices thus leaving less free amylose sites to interact with iodine (Kawai, Takato et al. 2012). The reduced capacity of amylose to bind with iodine resulted into a lower absorbance than control starch sample. The data clearly shows that when a fatty acid is binding amylose, the CI values decrease as the fatty acids chain length increased indicating the greater involvement of short chain fatty acids in the complex formation. It was assumed that the shorter chain fatty acids can be better dispersed in the gelatinized mixture thus facilitating their interactions with amylose and strengthens the CI complex. These results are similar to the previously reported studies (Kawai, Takato et al. 2012, Wang, Wang et al. 2016). On the other hand Fatty acid esters also showed affinity to form complexes with amylose. However there are no studies on their dispersivity in gelatinized starch. The starch-fatty acid mixture containing unsaturated component showed lower CI values probably due to the presence of double bond hindrance as similar behaviour was observed in the previous study by Kawai, Takato et al. (2012). However, more detailed future study is required as only single unsaturated fatty acid was selected in this study. The concluding results demonstrate that, carbon chain length is the major determinant of the starch-fatty acid complex formation. This interaction influences in the presence of double bonds in the carbon chain of fatty acids, manifesting the interacting capacity of different fatty acids in the complex 
formation. Moreover, complexation of amylose with lipid may impact significantly on the physical, mechanical and barrier properties of films.

\subsection{Thermal properties of RS-l-car -fatty acid mixture}

\subsubsection{Differential scanning calorimetry (DSC) and Thermogravimetric analysis (TGA)}

The thermal properties of starch-1-car films were analysed using DSC (Fig 2) with a typical endothermic transition occurring between $75^{\circ} \mathrm{C}$ and $110^{\circ} \mathrm{C}$ illustrating the melting of amyloseamylopectin crystallites. Previous studies reported that distribution of melting temperature of starch was found to be in the range of $67.2-81.1^{\circ} \mathrm{C}$ (Liu, Sun et al. 2016, Wang, Wang et al. 2016) which was consistent with above results. The appearance of an additional endothermic event at low temperature $\left(29^{\circ} \mathrm{C}\right.$ to $\left.62^{\circ} \mathrm{C}\right)$ was observed in case of LA (C12:0), PA (C16:0) and FAEs films attributed to the melting of free unbounded fatty acids which were not associated in the formation of complexes with amylose (Table 2, peak I). These observations are in agreement with Liu, Sun et al. (2016). No melting peak for OA was observed due to low melting temperature $\left(<20^{\circ} \mathrm{C}\right)$ of fatty acid. It is apparent that $\mathrm{T}_{\mathrm{m}}$ and $\Delta \mathrm{H}_{\mathrm{m}}$ values (Table 2, peak

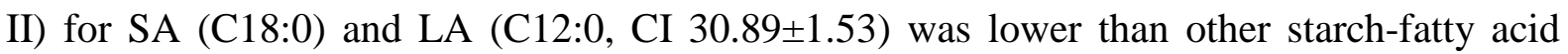
combinations in spite of higher complexity index. These results conclude that not all the molecules of fatty acid were involved in the complex formation and only the poorly bounded fatty acid molecule resulted into lower $\mathrm{T}_{\mathrm{m}}$ values. So it becomes more important to consider the other DSC parameters $\mathrm{T}_{\mathrm{g}}$ and $\Delta \mathrm{H}_{\mathrm{m}}$ as $\mathrm{T}_{\mathrm{m}}$ values does not appear to be a true indicator of compatibility between starch and fatty acids. Immiscibility between the different ingredients may also leads to the appearance of two $\mathrm{T}_{\mathrm{g}}$ values, corresponding to the pure phases (Ramos, Reinas et al. 2013). However this trend was not uniform across all the formulations. For example butyric acid and oleic acid showed single endothermic transition, resulting into peak 
convergence with starch gelatinization, signifying their interactions with starch components. A similar phenomenon of melting and gelatinization of starch-lipid mixture was observed in previous reported studies (Kawai, Takato et al. 2012, Wang, Wang et al. 2016). It is worth noting that the peak demonstrating the lipid melting was less prominent with short carbon chain length, signifying their more interactions with amylose (which leads to the formation of amylose-lipid complex). These observations may be due to the uniform dispersivity of hydrophobic components in the gelatinized starch. These DSC results (Fig 2) are in general agreement with CI complex formation that fatty acids with shorter chain can form stronger complexes with amylose (Table 1$)$. Gelatinization parameters $\left(\mathrm{T}_{\mathrm{m}}\right.$-melting temperature, $\mathrm{T}_{\mathrm{g}}$ glass transition and $\Delta \mathrm{H}_{\mathrm{m}}$ - melting enthalpy) derived from DSC thermograms are presented in

Table 2. The Fatty acids films exhibited lower $\Delta \mathrm{H}_{\mathrm{m}}$ values than FAEs treated films, suggesting that -carrageenan formed a stronger network with starch in the mixture. However, among the different fatty acids there was no uniform trend in the $\mathrm{T}_{\mathrm{g}}$ and $\Delta \mathrm{H}_{\mathrm{m}}$ values (Table 2). The $\Delta \mathrm{H}_{\mathrm{m}}$ is a measure of amount of energy required to break down the double helices of amyloseamylopectin crystallites (Wang and Copeland 2012) and amylose-lipid complexes. At high $\mathrm{T}_{\mathrm{m}}$, the decrease in $\Delta \mathrm{H}_{\mathrm{m}}$ shows only the melting of fatty acids and loosely bounded amyloseamylopectin components. Separate peaks $\left(90^{\circ} \mathrm{C}-110^{\circ} \mathrm{C}\right)$ of amylose-lipid complex (1.2$21.2 \%$ ) were observed in the previous studies (Liu, Sun et al. 2016), however no such peaks was observed at DSC temperatures below $200^{\circ} \mathrm{C}$ which may be due to strong complex formation between rice starch with different fatty acid components (15.7-36.5\%) and their method of formation, thus requiring higher temperatures for their melting. This assumption can be related to the thermogravimetric event occurring at the fourth heating regime $\left(400-600^{\circ} \mathrm{C}\right)$ of TGA study, given below.

TGA was performed to study the influence of thermal stability on the interaction of the film ingredients. Fig 3 shows the thermal events and corresponding weight loss of the each film 
sample. The thermogram results show the films were stable up to $70^{\circ} \mathrm{C}$. Four distinct regimes of degradation was observed. The first phase ranges of $100-200^{\circ} \mathrm{C}$, which is the characteristics event of a polysaccharide with hydrophilic nature (Basiak, Lenart et al. 2017). As could be seen, films treated with OA, (C18:1), BA (C4:0), LA (C12:0), PA (C16:0) and SA (C18:0) has showed the presence of first regime of degradation in the thermograms depicting a small weight loss \% ( 5-10), corresponding to the presence of moisture in films. A similar effect with initial degradation curve has been reported in the previously conducted study based on the starch based composite films (Podshivalov, Zakharova et al. 2017). The second phase of the thermogram $\left(250-275^{\circ} \mathrm{C}\right)$, represents the decomposition of glycerol rich phase and unbounded fatty acid components (Colussi, Pinto et al. 2017) where weight loss was comparatively higher $(12-40 \%)$. Third thermal phase was appeared in the range of $300-350^{\circ} \mathrm{C}$ which may be due to the decomposition of starch crystallites. Thermal events at higher temperatures denote the strong intermolecular interactions among the amylose components and lipid moieties. Findings of TGA analysis are in line with the previously reported studies (references). The final thermal event at higher temperature $\left(400-600^{\circ} \mathrm{C}\right)$ denotes the breakdown of strong amylose-lipid complexes, thus presented higher film stability (Cerqueira, Souza et al. 2012). It was interesting to note that weight loss $\%$ was minimum in case of FAEs and OA treated films suggesting that these films have higher thermal resistance.

317 In summary, the thermal properties of the RS- -car-lipid component films showed that, the amylose-lipid complex is a major determinant of film thermal properties. However, the DSC (fatty acids melting peak) and TGA (weight loss in the second regime) results showed that not all the fatty acids were involved in the complex formation and more detailed future studies are required to understand the profound mechanism of complex formation. 


\subsection{Physical properties}

\subsubsection{Thickness}

325

Thickness is directly related to the barrier and optical properties of films. In this study the thickness of RS-ı-car film ranged between 0.07 to $0.39 \mathrm{~mm}$ for the films with different fatty acids (Fig 4a). Films with FAEs $(0.08 \mathrm{~mm})$, butyric acid $(0.07 \mathrm{~mm})$, stearic acid $(0.09 \mathrm{~mm})$ showed significantly lower thickness values than other films $(p<0.05)$. In comparison, films with oleic acid and palmitic acid were four times thicker than the control film. This may be due to the over accumulation of melted fatty acid on the film surface which increases the thickness of resultant film. However, there is little information in the literature related to the effect of fatty acid on the thickness of edible films.

\subsubsection{Film solubility}

Solubility describes the water resistance of films when applied on fresh produce (Cerqueira, Souza et al. 2012). Solubility of starch-carrageenan films with different lipid components is presented in Table 1 and shows that the solubility power of RS-1-car films decreased with the incorporation of hydrophobic components, where the values ranged from $50.3 \%$ to $82.7 \%$. Significant differences exist in the mean values of different fatty acids and solubility vary with the type of added lipids ( $p>0.05)$. These variations in the film solubility may be influenced by CI complex formation. Low solubility values of LA and BA could be attributed to the formation of strong stable helices formed between amylose and lipid content which formed an insoluble film on the starch granule surface and delayed the transportation of water into the granule. In addition to that fatty acids may restrict the swelling of starch granules and inhibit the leaching of amylose, which in turn causes to lower solubility of the starch films. Results of this study are similar to previously reported work where amylose-lipid complexes reduces the solubility 
of starch composite films (Copeland, Blazek et al. 2009). The mobility of the matrix ( $\mathrm{T}_{\mathrm{g}}$ ) has also influenced the starch solubility power as water molecules can be trapped more easily in to the spaces between the helices resulting in an increase in water solubility. The control film showed lower $\mathrm{T}_{\mathrm{g}}$ values $\left(37.9^{\circ} \mathrm{C}\right)$ than fatty acid treated films. Lower solubility values of FAEs, may be due to the unavailability of free $\mathrm{OH}$ groups for the interaction with water.

\subsection{Barrier property-water vapour permeability (WVP)}

354

355

356

357

Fatty acids have been studied as a good barrier to moisture (Schmidt, Porto et al. 2013). In this experiment WVP values significantly varied between the different polymer-lipid combinations (Fig 4b). Rice starch based film with different hydrophobic components showed lower permeability values as compared to the control film (without fatty acid), demonstrating the impact of hydrophobic components on the permeability of starch based film. Lowest WVP values was observed in case of film samples with FAEs $\left(1.18 \times 10-11 \mathrm{gs}^{-1} \mathrm{~m}^{-1} \mathrm{~Pa}^{-1}\right)$ comparatively six times lower than control film samples $\left(7.56 \times 10^{-11} \mathrm{gs}^{-1} \mathrm{~m}^{-1} \mathrm{~Pa}^{-1}\right)$ which is a promising value for potential fruit coating applications. Results of this study are consistent with the previously reported data where the addition of FAEs has been studied to improve the permeability values of films compared to fatty acids (Jongjareonrak, Benjakul et al. 2006). In this experiment the higher permeability value of the control film may be due to lack of strong network crosslinking via covalent and non-covalent bonds resulting into more interstitial spacing between molecules and as a consequence led to higher diffusion rate across the membrane. Based on the previous studies on different types of lipids with different matrices, WVP has been shown to decrease as increase in fatty acids chain length (McHugh and Krochta 1994). However, in this study there was no uniform pattern of permeability based on chain length was observed. This is probably due to the differences in the fatty acids ability to forms 
a complex with amylose and amylopectin. This reinforces the fact that there might be other bonding and interactions effects related to the structural arrangement of lipid in the film and with other ingredients which plays an important role in governing the permeability of starch gel.

\subsection{Optical properties-opacity}

Opacity of the films are directly related to the microstructural properties and affected by surface morphology and internal heterogeneity of films (Jiménez, Fabra et al. 2012). The opacity of RS-1-car film is presented in Fig 5a and shows that opacity\% was lower in case of fatty acids treated films as compared with control films, signifying their higher transparency value. However, non-significant differences $(p>0.05)$ in the FAEs and control films values were observed and films were more transparent. The incorporation of lipids to the hydrocolloid mixture resulted a decrease in the transparency values probably due to the differences in the refractive index of the dispersed and continuous phase. The results of this study are similar to those reported previously which found that incorporation of fatty acids lowered the transparency of films (Thakur, Saberi et al., Yang and Paulson 2000, Fernandez, de Apodaca et al. 2007).

\subsection{Mechanical properties- tensile strength (TS) and elongation at break (EAB)}

The tensile strength (TS) and elongation at break (EAB) of RS-ı-car films with different fatty acids are presented in Fig 5b, c and the results shows that films prepared from OA exhibited significantly higher $(p<0.05)$ strength at maximum load, which possibly due to higher thickness of the OA films. Mechanical properties have been reported to impair with the addition of fatty acids (Rocca-Smith, Marcuzzo et al. 2016). However, in this experiment however, TS was 
found to be improved, with the addition of FA in comparison to control film samples, which may be due to the interactions and compatibility of between components, further signifying the positive effect of hydrophobic plasticizer on the RS-1-car film. In the context of starch-fatty acid composite mixture, the improved film mechanical properties may be due to the interaction of amylose and amylopectin with lipids during the gelatinization process. It is interesting to note that BA with highest CI \% (36.5) also showed lowest tensile values. The poor mechanical properties of the films may be due to the phase separation, which leads to the formation of discontinuous zones, as observed in SEM micrographs (Fig 1). The TS of stearic acid (143.23 $\mathrm{N} / \mathrm{m})$ and palmitic acid $(145.56 \mathrm{~N} / \mathrm{m})$ had minimum or no impact on the mechanical properties of starch films, possibly due to their lower CI values $18.8 \%, 17.9 \%$. Similar explanations can be provided for the films incorporated with FAEs and lauric acid. Moreover, it is worth noting that EAB values for the films plasticized with PA were significantly higher $(p<0.05)$ than control and films incorporated with other fatty acids. The non-covalent intermolecular crosslinking is pivotal to the development of a 3-dimensionsal network. Hence a likely reason for the varying tensile strength and EAB of RS-l-car -fatty acids films could be due to the lack of interchain associations between linear starch molecules as a consequence of inhibition of extensive exudation of amylose and amylopectin by lipids and thereby reduces the interaction. The results of this study are similar to previous reports which showed the variations in the starch mechanical properties were due to the influence of lipids on the gelatinization process (Biliaderis and Tonogai 1991). In conclusion, we showed mechanical properties are dependent on the complexing of amylose with hydrophobic ligands. 


\section{Conclusion}

418 This study investigated the structural and permeability properties of starch film as influenced 419 by the incorporation of fatty acids components. From the study we conclude that, different fatty 420 acids showed varying complex formation ability with the amylose depending on the carbon 421 chain length. The influence of these intermolecular interactions was apparently observed on 422 the films physical, mechanical and barrier properties with short chain fatty acids showing a more positive effect presumably due to the formation of more stable complexes with short

424 chain fatty acids. Study also confirmed that not all the fatty acids molecules participates in the 425 complex formation as revealed by DSC and TGA, and therefore, the mechanism underlying the complex formation between amylose and lipid need further investigation. Overall, the FAEs

427 films showed lower thickness, opacity and WVP values, which are promising indicators for a starch based composite film for fruit coating applications.

\section{Acknowledgement}

431 This work was supported by the University of Newcastle, Australian Research Council (ARC)

432 Training Centre for Food and Beverage Supply Chain and Optimisation (IC140100032). NSW

433 Department of Primary Industries is a partner organisation in the Training Centre. We greatly 434 acknowledge University of Newcastle EMX unit, for providing access to SEM and XRD 435 instruments. 
Acosta, S., et al. (2015). "Physical properties and stability of starch-gelatin based films as affected by the addition of esters of fatty acids." Food Hydrocolloids 49: 135-143.

Basiak, E., et al. (2017). "Effect of starch type on the physico-chemical properties of edible films." International Journal of Biological Macromolecules 98: 348-356.

445
Bhat, F. M. and C. S. Riar (2016). "Effect of amylose, particle size \&amp; morphology on the functionality of starches of traditional rice cultivars." International Journal of Biological Macromolecules 92: 637-644.

Biliaderis, C. G. and J. R. Tonogai (1991). "Influence of lipids on the thermal and mechanical properties of concentrated starch gels." Journal of Agricultural and Food Chemistry 39(5): 833-840.

Cerqueira, M. A., et al. (2012). "Effect of glycerol and corn oil on physicochemical properties of polysaccharide films - A comparative study." Food Hydrocolloids 27(1): 175-184.

Chiumarelli, M. and M. D. Hubinger (2014). "Evaluation of edible films and coatings formulated with cassava starch, glycerol, carnauba wax and stearic acid." Food Hydrocolloids 38: 20-27.

Colussi, R., et al. (2017). "Acetylated rice starches films with different levels of amylose: Mechanical, water vapor barrier, thermal, and biodegradability properties." Food Chemistry 221: 1614-1620.

Copeland, L., et al. (2009). "Form and functionality of starch." Food Hydrocolloids 23(6): 1527-1534.

Dhall, R. K. (2013). "Advances in edible coatings for fresh fruits and vegetables: a review." Critical Reviews in Food Science and Nutrition 53(5): 435-450.

Fernandez, L., et al. (2007). "Effect of the unsaturation degree and concentration of fatty acids on the properties of WPI-based edible films." European Food Research and Technology 224(4): 415-420.

González, R. M. and M. P. Villanueva (2011). 19 - Starch-based polymers for food packaging A2 Lagarón, José-María. Multifunctional and Nanoreinforced Polymers for Food Packaging, Woodhead Publishing: 527-570.

Jiménez, A., et al. (2012). "Effect of re-crystallization on tensile, optical and water vapour barrier properties of corn starch films containing fatty acids." Food Hydrocolloids 26(1): 302-310.

Jongjareonrak, A., et al. (2006). "Fatty acids and their sucrose esters affect the properties of fish skin gelatin-based film." European Food Research and Technology 222(5): 650-657. 
Karbowiak, T., et al. (2006). "Effect of plasticizers (water and glycerol) on the diffusion of a small molecule in iota-carrageenan biopolymer films for edible coating application." Biomacromolecules 7(6): 2011-2019.

483

484

485

486

487

488

489

490

491

492

493

494

495

496

497

498

499

500

501

502

503

504

505

506

507

508

509

510

511

512

513

514

515

516

517

518

519

520

521
Kawai, K., et al. (2012). "Complex formation, thermal properties, and in-vitro digestibility of gelatinized potato starch-fatty acid mixtures." Food Hydrocolloids 27(1): 228-234.

Kowalczyk, D. and B. Baraniak (2011). "Effects of plasticizers, pH and heating of film-forming solution on the properties of pea protein isolate films." Journal of Food Engineering 105(2): 295-305.

Liu, P., et al. (2016). "Effects of fatty acids with different degree of unsaturation on properties of sweet potato starch-based films." Food Hydrocolloids 61: 351-357.

Martins, J. T., et al. (2012). "Synergistic effects between $\mathrm{k}$-carrageenan and locust bean gum on physicochemical properties of edible films made thereof." Food Hydrocolloids 29(2): 280-289.

McHugh, T. H. and J. M. Krochta (1994). "Water vapor permeability properties of edible whey protein-lipid emulsion films." Journal of the American Oil Chemists' Society 71(3): 307-312.

Podshivalov, A., et al. (2017). "Gelatin/potato starch edible biocomposite films: Correlation between morphology and physical properties." Carbohydrate Polymers 157: 1162-1172.

Ramos, Ó. L., et al. (2013). "Effect of whey protein purity and glycerol content upon physical properties of edible films manufactured therefrom." Food Hydrocolloids 30(1): 110-122.

Rocca-Smith, J. R., et al. (2016). "Effect of lipid incorporation on functional properties of wheat gluten based edible films." Journal of Cereal Science 69: 275-282.

Saberi, B., et al. (2016). "Optimization of physical and optical properties of biodegradable edible films based on pea starch and guar gum." Industrial Crops and Products 86: 342-352.

Schmidt, V. C. R., et al. (2013). "Water vapor barrier and mechanical properties of starch films containing stearic acid." Industrial Crops and Products 41: 227-234.

Slavutsky, A. M. and M. A. Bertuzzi (2016). "Improvement of water barrier properties of starch films by lipid nanolamination." Food Packaging and Shelf Life 7: 41-46.

Thakur, R., et al. "Effect of Starch Physiology, Gelatinization and Retrogradation on the Attributes of Rice Starch-ı-Carrageenan Film." Starch - Stärke: 1700099-n/a.

Thakur, R., et al. "Characterization of Rice Starch- l-Carrageenan Biodegradable Edible Film. Effect of Stearic Acid on the Film Properties." International Journal of Biological Macromolecules. 
Thakur, R., et al. (2016). "Characterization of rice starch-iota-carrageenan biodegradable edible film. Effect of stearic acid on the film properties." Int J Biol Macromol 93(Pt A): 952-960.

Vieira, M. G. A., et al. (2011). "Natural-based plasticizers and biopolymer films: A review." European Polymer Journal 47(3): 254-263.

Wang, S. and L. Copeland (2012). "Phase transitions of pea starch over a wide range of water content." J Agric Food Chem 60(25): 6439-6446.

Wang, S., et al. (2016). "Effect of fatty acids on functional properties of normal wheat and waxy wheat starches: A structural basis." Food Chem 190: 285-292.

Wang, S., et al. (2016). "Effect of fatty acids on functional properties of normal wheat and waxy wheat starches: A structural basis." Food Chemistry 190: 285-292.

Wang, S., et al. (2016). "Changes of multi-scale structure during mimicked DSC heating reveal the nature of starch gelatinization." Scientific Reports 6: 28271.

Wani, A. A., et al. (2012). "Rice Starch Diversity: Effects on Structural, Morphological, Thermal, and Physicochemical Properties-A Review." Comprehensive Reviews in Food Science and Food Safety 11(5): 417-436.

Yang, L. and A. Paulson (2000). "Effects of lipids on mechanical and moisture barrier properties of edible gellan film." Food Research International 33(7): 571-578. 